\title{
Documenting the value of OPAT: Outcome studies and patient registries
}

\author{
Alan D Tice MD FACP
}

$\mathrm{M}$ edical care in the United States is changing rapidly. New and useful products and procedures are brought to the market almost daily. At the same time, there are increasing concerns about the cost of medical care and the reluctance to pay for it. The private companies who pay for the spiraling cost of medical benefits for their employees are concerned about their ability to pay for benefits while remaining competitive. The primary insurer, the federal Health Care Financing Administration, will be headed toward bankruptcy if it continues to provide retired Medicare beneficiaries the health care that their elected officials have promised. Although there will almost certainly be another increase in taxation to make up for the shortfall, it is only a temporary solution.

As a result, there has been a critical look at health care to generate ideas for 'reform', and a search for answers about costs and quality of care. The now defunct Office of Technology Assessment provided some disturbing, yet truthful insight to the United States Congress in 1994 with their finding that: "The justification for most medical practices used in the United States today rests on the experience and expertise of the clinicians and patients rather than on objective evidence that these practices can measurably improve people's health" (1).

In an effort to reduce medical costs through the elimination of unnecessary services, the concept of 'managed care' has evolved with an increasing impact on medicine and society (2). Physicians are no longer simply asked their opinions but also to justify them. If they cannot, benefits may be denied. Health care reform has been an anathema to many doctors, but a boon to attorneys, administrators and entrepreneurs. It also led to greater accountability and a re-examination of the benefit or relative value of many medicines and procedures. The medical profession has begun to study quality of care and to look for indicators of quality, but is at a disadvantage com- pared with the businessmen who have a far easier measurement tool - money. A growing science of quality assurance or evidence-based medicine helps in decision-making and allocation of resources. Every field of medicine is looking for outcome measures that are useful in assessing the quality of care and justifying the therapies provided.

Outpatient parenteral antibiotic therapy (OPAT) is in an enviable position compared with many other recent advances in medicine. It brings an improvement in care to selected patients but also cost savings. This is a rare combination of benefits for any new program in modern medicine, but the need for quality assurance remains, with fierce competition among home care providers as they vie for business and contracts from insurance companies. OPAT is also in need of continued reexamination because it is a relatively new form of medical therapy that occurs outside the safeguards and controlled environment of the hospital. Questions remain about undiscovered problems, standards of care and limitations to the benefits. How far can it be pushed before there are safety problems?

One of the most-standardized and universally accepted measures of outcome is cost. The cost savings of OPAT have been well studied. In a 1978 article, Antoniskis and colleagues (3) compared the cost of care for patients treated in hospital with those treated for an average of 22 days outside hospital a savings of US\$165/day. Later studies examined different aspects of cost, such as transportation, child care, laundry, food and the impact on the family (Table 1) (3-8). Additional considerations included the economic advantage to the patient of returning to work or school despite ongoing OPAT $(9,10)$. The most recent article by Hindes et al (8) investigated the financial aspects of OPAT for Medicare patients. They modelled a cost formula based on bed occupancy. The different series in 
TABLE 1

Estimated cost savings of outpatient parenteral antibiotic therapy program in the United States

\begin{tabular}{|c|c|c|c|c|c|c|}
\hline Reference & Study & Cases & Primary infections & Primary antibiotics & Days of therapy & $\begin{array}{c}\text { Savings per day } \\
\text { (per case) }^{*}\end{array}$ \\
\hline 3 & Antoniskis et al, 1978 & 13 & $\begin{array}{c}\text { Osteomyelitis, bacteremia, } \\
\text { endocarditis }\end{array}$ & Various & 22 & $\$ 165(\$ 3,700)$ \\
\hline 4 & Poretz et al, 1984 & 83 & Various & Ceftriaxone & 18 & $>\$ 150(\$ 6,588)$ \\
\hline 5 & Kind et al, 1985 & 315 & $\begin{array}{l}\text { Bone, joint, skin } \\
\text { and soft tissue }\end{array}$ & Various & - & $\$ 350(\$ 4,725)$ \\
\hline 6 & Kane et al, 1988 & 27 & Cystic fibrosis & $\begin{array}{l}\text { Aminoglycosides }+ \\
\text { ticarcillin piperacillin }\end{array}$ & 10.2 & $\$ 609(\$ 5,017)$ \\
\hline 7 & Williams et al, 1993 & 56 & $\begin{array}{c}\text { Cellulitis, osteomyelitis, } \\
\text { others }\end{array}$ & Primarily ceftriaxone & 5.1 & $\$ 262(\$ 3,228)$ \\
\hline 8 & Hindes et al, 1995 & 48 & $\begin{array}{c}\text { Osteomyelitis, } \\
\text { endocarditis, others }\end{array}$ & Various & 22 & $\$ 276(\$ 6,111)$ \\
\hline
\end{tabular}

*Values are in US dollars

TABLE 2

Outcome indicators for outpatient parenteral antibiotic therapy

\begin{tabular}{ll}
\hline Indicator & Possible outcome \\
\hline $\begin{array}{c}\text { Bacterial outcome at the end of } \\
\text { therapy }\end{array}$ & $\begin{array}{c}\text { Culture negative, persistent } \\
\text { organism or superinfection } \\
\text { Clinical outcome at the end of } \\
\text { therapy }\end{array}$ \\
$\begin{array}{l}\text { Improved, no change or failed } \\
\text { Batient satisfaction }\end{array}$ & $\begin{array}{l}\text { Would use OPAT again } \\
\text { Death, noncompliance or } \\
\text { hospitalization }\end{array}$ \\
Change in antibiotic & $\begin{array}{c}\text { Clinical failure, adverse effect, } \\
\text { resistant organism or } \\
\text { super-infection }\end{array}$ \\
\hline
\end{tabular}

Table 1 report actual cost savings of US $\$ 160$ to over US $\$ 600$ per day. On a per case basis, the range is from US\$3,200 to over US\$6,000.

From the perspective of the insurance company or payer, cost savings may be even greater. In 1996, the average charge for a day in the hospital was US $\$ 1,000$ (11). This contrasts with the charges of a home infusion company for OPAT, which was US $\$ 200$ to US\$300 per day in 1994 (12). These charges are likely less now with the competition that exists among home care providers.

The financial incentives for payers to discharge patients on OPAT are now so great that questions arise about whether we are reaching the limits of safety and appropriate care. Obviously, not everyone on intravenous (IV) antibiotic therapy can be treated as an outpatient, but what are the limits and what are the indicators of those limits? This concern, coupled with the increasing competition based on price, has caused infusion therapy providers to cut back on their costs by using staff with less training and education, IV push infusions, different delivery modes and reduced staff. Again, what are the limits? To face these challenges, the Infectious Disease Society of America (IDSA) has published practice guidelines on OPAT that outline the responsibilities of OPAT providers and a list of factors prescribing physicians should look for in a provider before authorizing home or outpatient therapy (13). In addi- tion, there is an escalating interest in quality assurance measurements and outcomes indicators as evidenced by the requirements for the Health Plan Employer Data and Information Set (HEDIS) survey by private insurance payers and the ORYX initiative by the Joint Commission for the Accreditation of Health Care Organizations (JCAHO). To be accredited, JCAHO will require that ambulatory care providers have a system for monitoring outcomes in place by the start of 2001 . During the first year, ORYX will be looking at five indicators that must include at least $20 \%$ of the population served (14). In addition, the need for quality assurance has become economic because many insurers will not pay for OPAT unless a provider is accredited.

Outcome indicators for OPAT have been studied by JCAHO. In fact, they attempted to establish a network of sites using standardized indicators a few years ago, but this was too large a project (15). Many home infusion companies have their own set of indicators and accumulate information, but, with a few exceptions, they do not share or publish their information (16).

A list of considerations for outcome measurements is given in Table 2. The parameters are presently part of a multicentre registry started by the Outpatient Intravenous Infusion Therapy Association (OPIVITA) with Health Data Research (17), which will meet the ORYX requirements for JCAHO accreditation.

The clinical parameters of bacterial outcomes and clinical outcomes measured on the last day of therapy are indicators of the effectiveness of therapy. They may be useful in comparing different antibiotics or dosing regimens in the treatment of the same or comparable infections. They also allow some comparison of different OPAT programs or within the same program over time. Table 3 shows clinical and bacterial outcomes from several series. To provide greater insight into the response to therapy, follow-up information is necessary. This creates a significant administrative and staff burden, but it is possible for targeted studies or diseases.

Patient satisfaction is an important indicator that is often commented on in the literature, but seldom quantified. Infections Limited asks the patient to fill out a survey questionnaire on the last day of therapy. One of the questions asked is 
TABLE 3

Bacterial and clinical outcomes

\begin{tabular}{|c|c|c|c|}
\hline Study & Cases & Bacterial outcome & Clinical outcome \\
\hline $\begin{array}{l}\text { Stiver } 1982 \\
(26)\end{array}$ & 95 & $\begin{array}{l}72 \text { culture negative } \\
(76 \%) \\
20 \text { culture positive }(21 \%)\end{array}$ & $\begin{array}{l}92 \mathrm{~S} / \mathrm{S} \text { resolved } \\
(97 \%)\end{array}$ \\
\hline $\begin{array}{l}\text { Eron } 1988 \\
(27)\end{array}$ & 2096 & $\begin{array}{l}89 \% \text { responded } \\
\text { favourably }\end{array}$ & $\begin{array}{l}89 \% \text { responded } \\
\text { favourably }\end{array}$ \\
\hline $\begin{array}{l}\text { Poretz } 1994 \\
\text { (28) }\end{array}$ & 118 & $94 \%$ bacteria eradicated & $\begin{array}{l}\text { 97.5\% cure or } \\
\text { improvement }\end{array}$ \\
\hline $\begin{array}{l}\text { Williams } \\
1993 \text { (29) }\end{array}$ & 56 & $95 \%$ resolved & $95 \%$ improvement \\
\hline $\begin{array}{l}\text { Tice } 1995 \\
\text { (30) }\end{array}$ & 538 & $\begin{array}{l}265 \text { evaluable eradicated } \\
(92 \%)\end{array}$ & $\begin{array}{l}491 \text { evaluable } \\
\text { improvement } \\
(98.6 \%)\end{array}$ \\
\hline
\end{tabular}

whether they would prefer hospital care or outpatient therapy if they required another course of IV therapy. So far, the results have been excellent; 95\% responded that they would definitely prefer OPAT, $4.0 \%$ would probably use OPAT again and only $0.5 \%$ would probably not use OPAT again (18). Patient comments and preferences may be extremely useful in understanding the patients' perspective and insight. They may also be helpful in dealing with payers who may be circumspect about the value of OPAT $(9,19)$.

Reasons for breaks in OPAT or failure to complete a plan of treatment should also be investigated and tracked. The usual reasons for failure to complete a course of therapy include death, patient compliance or hospitalization. Table 4 displays results from several large series. Deaths may also be a useful indicator of outcome. The series by Williams (20) in Minneapolis noted that there were no deaths in more than 1500 patients, but they looked only at deaths that occurred due to the program. The series by Tice (21) looked at all deaths that occurred while on OPAT and found this frequency to be less than $1 \%$. Often, these patients are terminal, with either human immunodeficiency virus (HIV) or malignancies, and have an expected fatal outcome. The patients who died had comorbid conditions such as heart disease, diabetes and lung disease for which a sudden acute event leading to death was not unexpected. Tice did not find any deaths to have occurred while on the program. Each death that occurs while on the program should be viewed as an opportunity to learn whether the
TABLE 4

Program outcomes

\begin{tabular}{lcccc}
\hline \multicolumn{5}{c}{ Study } \\
Outcomes & Williams & Tice 1995 & Stiver 1982 & NAIT \\
(1995 (29) & $\mathbf{( 3 0 )}$ & $\mathbf{( 2 6 )}$ & $\mathbf{1 9 9 2}(\mathbf{3 1 )}$ \\
\hline Courses & 1500 & 538 & 102 & 623 \\
Deaths (\%) & 0 & 0.2 & 1.05 & 10.3 \\
Compliance (\%) & $*$ & 0.6 & $*$ & $*$ \\
Hospitalized (\%) & 5 to 6 & 7.8 & 10.5 & 6.1 \\
\hline
\end{tabular}

*Not documented. NAIT National Alliance for Infusion Therapy

safety factors of a program could be improved or if patient selection factors should be changed.

Compliance may also be a useful indicator of the quality of a program or may reflect a particularly difficult patient group. If a person lives too far away or has transportation problems, they may not be able to be compliant; these factors should be carefully assessed before OPAT is started. Drug or alcohol problems may also be reasons for noncompliance, even though they are not always apparent on initial evaluation in the office or hospital. Some patients may not return for financial reasons, especially if they falsified their initial insurance information or if they are asked to pay a certain amount with each visit and are unable to do so. A group of patients who are simply noncompliant also exists. They may already have been advised that hospitalization is necessary, but have refused. In a last ditch effort, they may be offered OPAT, but fail to comply with the advice. An evaluation for mental health problems may also be helpful, including the possibility of involuntary confinement for medical reasons.

Hospitalization may also be viewed as an adverse event on OPAT. The incidence varies from 5 to $10 \%$ (20-23). Hospitalizations are usually due to medical problems or elective surgery rather than the infection or problems with OPAT. There are urgent problems that arise during OPAT that should be considered, such as phlebitis, emboli from endocarditis, heart disease and lung problems that may necessitate urgent admission or surgery. The ability to respond is usually not as good at home; hence, this should be considered in decision-making and patients informed. Although there are risks with OPAT, these should be weighed against the risks of hospitalization. This is, however, an area of concern in understanding how ag-

\section{TABLE 5}

Incidence of adverse event causing change of antibiotic

\begin{tabular}{|c|c|c|c|c|c|}
\hline Antibiotic & Courses & Adverse events (\%) & Days of OPAT & $\begin{array}{c}\text { Adverse events per } \\
1000 \text { days }\end{array}$ & $\begin{array}{l}\text { OPAT days until ad- } \\
\text { verse event (range) }\end{array}$ \\
\hline Ceftriaxone & 257 & $8(3)$ & 4049 & 1.98 & $25(1-30)$ \\
\hline Vancomycin & 134 & $11(8)$ & 3399 & 3.24 & $31.4(10-94)$ \\
\hline Ceftazidime & 31 & 0 & 568 & 0 & \\
\hline Cefazolin & 29 & 0 & 546 & 0 & \\
\hline Oxacillin/nafcillin & 26 & $3(12)$ & 524 & 5.73 & $24.3(1-41)$ \\
\hline Gentamicin/ tobramycin & 15 & 0 & 254 & 0 & \\
\hline Clindamycin & 16 & $2(12)$ & 284 & 7.04 & $9(6-12)$ \\
\hline Penicillin & 12 & $1(8)$ & 241 & 4.15 & 26 \\
\hline
\end{tabular}

Adapted from reference 17. OPAT Outpatient parenteral antibiotic therapy 
gressive to be and what diseases are more or less likely to result in an emergency admission or urgent surgery. Diabetic foot infections are some of the most frequent failures in our experience because of the difficulty in controlling glucose levels and activity outside the hospital.

A change in antibiotic therapy may also be a useful outcome indicator. This has been used with patients with fever and neutropenia (24). It also provides some reflection of the need for physician involvement to optimize care. Reasons for a change in antibiotic therapy may also be useful to examine, including whether the decision to change drug was based on an adverse event, clinical failure, new susceptibility results or super infections. Table 5 gives the incidence of change in antibiotic therapy gathered from data accumulated by the OPAT registry through OPIVITA (17). The number of courses of ther-

\section{REFERENCES}

1. Technology Assessment Board of the 103rd Congress. Summary. In: Office of Technology Assessment, ed. Identifying Health Technologies That Work: Searching for Evidence. Washington, DC: United States Government Printing Office; 1994:1-17.

2. Tice AD, Slama TG, Berman S, et al. Managed care and the infectious diseases specialist. Clin Infect Dis 1996;23:341-68.

3. Antoniskis A, Anderson BC, Van Volkinburg EJ, Jackson JM, Gilbert DN. Feasibility of outpatient self-administration of parenteral antibiotics. West J Med 1978;128:203-6.

4. Poretz DM, Woolard D, Eron LJ, Goldenberg RI, Rising J, Sparks S. Outpatient use of ceftriaxone: a cost-benefit analysis. Am J Med 1984;77:77-83.

5. Kind AC, Williams DN, Gibson J. Outpatient intravenous antibiotic therapy. Ten years' experience. Postgrad Med 1985; $77: 105-8,111$.

6. Kane RE, Jennison K, Wood C, Black PG, Herbst JJ. Cost savings and economic considerations using home intravenous antibiotic therapy for cystic fibrosis patients. Pediatr Pulmonol 1988;4:84-9.

7. Williams DN, Bosch D, Boots J, Schneider J. Safety, efficacy, and cost savings in an outpatient intravenous antibiotic program. Clin Ther 1993;15:169-79.

8. Hindes R, Winkler C, Kane P, Kunkel M. Outpatient intravenous antibiotic therapy in Medicare patients: cost-savings analysis. Infect Dis Clin Pract 1995;4:211-7.

9. Williams DN. Home intravenous anti-infective therapy (HIVAT): do the benefits outweigh the risks? Drug Saf 1996;14:1-7.

10. Poretz DM, Eron LJ, Goldenberg RI, et al. Intravenous antibiotic therapy in an outpatient setting. JAMA 1982;248:336-9.

11. American Hospital Association. Hospital statistics. 1998. Chicago, Healthcare InfoSource, Inc, 1998.

12. Birnbaum HG, Tang M. The Home Infusion Therapy/Relative Benefit Index: summary of an analysis using insurance claims data. Med Care 1998;36:757-65.

13. Williams DN, Rehm SJ, Tice AD, Bradley JS, Kind AC, Craig WA. Practice guidelines for community-based parenteral anti-infective therapy. ISDA Practice Guidelines Committee. Clin Infect Dis 1997;25:787-801.

14. Barrell JM. ORYX: outcomes measurement and accreditation. Infusion. 1998;May:37-9.

15. Kunkel MJ. Outpatient parenteral antibiotic therapy. Management of serious infections. Part I: Medical, socioeconomic, and legal issues. Quality assurance. Hosp Pract 1993;28(Suppl 1):33-8.

16. Poole SM, Vasilios AN. Outcomes measurements: making sense of the data. Infusion 1998;May:25-8. apy is limited for antibiotics other than ceftriaxone and vancomycin, but some trends are apparent. This information provides additional factors to consider in regard to the selection of antimicrobials for outpatient therapy.

Networks collect useful information that can be compared among centres and over time. The accumulation of this information will allow sufficient numbers for statistical insight and understanding. It is hoped that organizations such as OPIVITA will be able to accumulate enough information about antibiotic efficacy and safety so that clear guidelines can be developed (17).

ACKNOWLEDGEMENTS: The author thanks Pamela A Hoaglund for her assistance in writing this article.

17. Kunkel MJ. Outcomes measurement in OPAT: why and how. In: Tice AD. Outpatient Parenteral Antimicrobial Therapy: Current Status. New York: Scientific American Inc, 1997:50-4.

18. Tice AD. Alternate site infusion: the physician-directed, office-based model. J Intraven Nurs 1996;19:188-93.

19. Coley CM, Li Y-H, Medsger AR, et al. Preferences for home vs hospital care among low-risk patients with community-acquired pneumonia. Arch Intern Med 1996;156:1565-71.

20. Williams D. Home intravenous antibiotic therapy (HIVAT): indications, patients and antimicrobial agents. Int J Antimicrob Agents 1995;5:3-8.

21. Tice AD. The importance of teamwork for outpatient parenteral antibiotic therapy. Int J Antimicrob Agents 1995;5:13-7.

22. Mustafa MM, Aquino VM, Pappo A, Tkaczewski I, Buchanan GR. A pilot study of outpatient management of febrile neutropenic children with cancer at low risk of bacteremia. J Pediatr 1996;128:847-9.

23. Talcott JA, Whalen A, Clark J, Rieker PP, Finberg R. Home antibiotic therapy for low-risk cancer patients with fever and neutropenia: a pilot study of 30 patients based on a validated prediction rule. J Clin Oncol 1994;12:107-14.

24. Freifeld AG, Pizzo PA. The outpatient management of febrile neutropenia in cancer patients. Oncology 1996;10:599-606,611-2.

25. Dahlgren AF. Adverse drug reactions in home care patients receiving nafcillin or oxacillin. Am J Health Syst Pharm 1997;54:1176-9.

26. Stiver HG, Trosky SK, Coté DD, et al. Self-administration of IV antibiotics: An Efficient cost-effective home care program. CMAJ 1982;127:207-11.

27. Eron LJ. Antibiotic therapy in an outpatient setting: Report of a joint venture program. Hosp Formul 1988;23:440-447.

28. Poretz DM. Tratment of skin and soft-tissue infections utilizing an outpatient parenteral drug delivery device: A multicenter trial. Am J Med 1994;97:23-7.

29 Williams DN, Bosch D, Boots J, Schneider J. Safety, efficacy, and cost savings in an outpatient intravenous antibiotic program. Clin Ther 1993;15:169-70.

30. Tice AD. Patient selection criteria for outpatient parenteral antibiotic therapy: Expereicne with a physician-directed, clinic-bassed program for outpatient parenteral antibiotic therapy in the USA. Eur J Clin Microbiol Infect Dis 1995; 14:655-61.

31. Winters RW, Parver AK, Sansbury JD. Home infusion therapy: A service and demographic profile. A report for the National Alliance for Infusion Therapy. Washington: National Alliance for Infusion Therapy, 1992:1-61. 


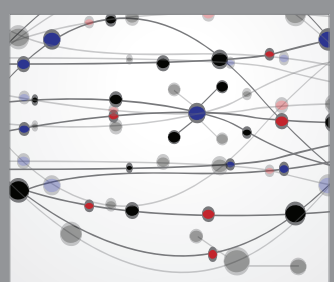

The Scientific World Journal
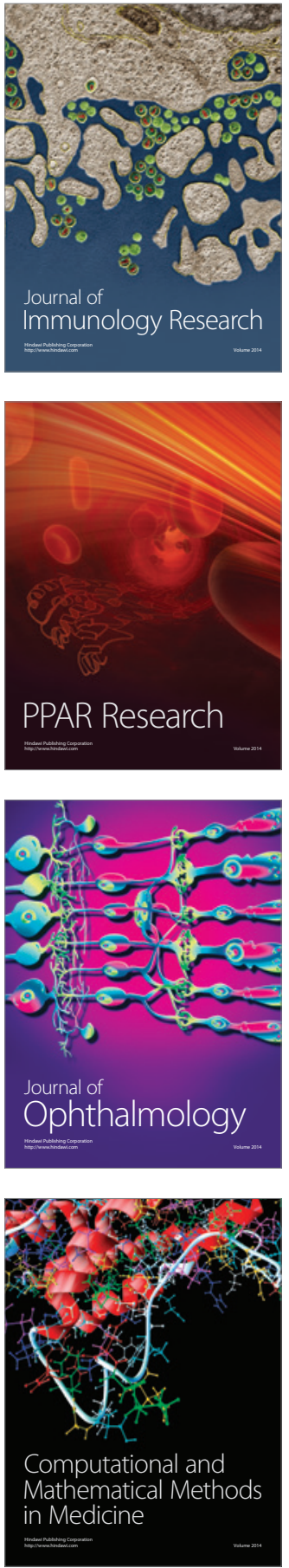

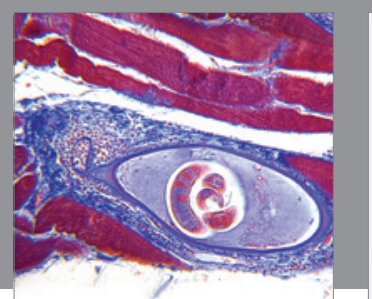

Gastroenterology Research and Practice

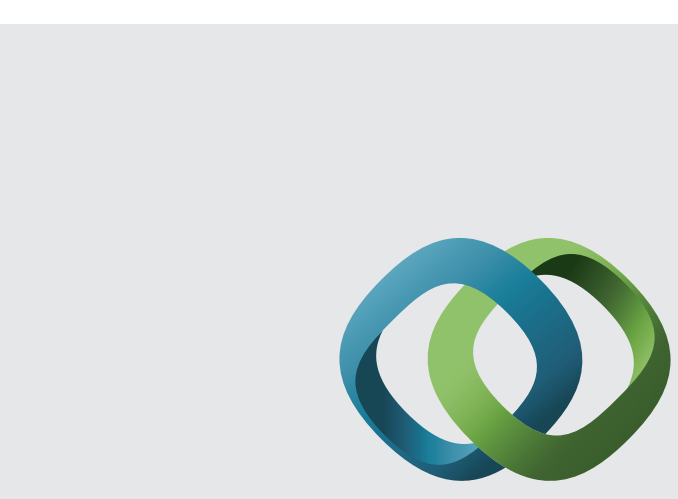

\section{Hindawi}

Submit your manuscripts at

http://www.hindawi.com
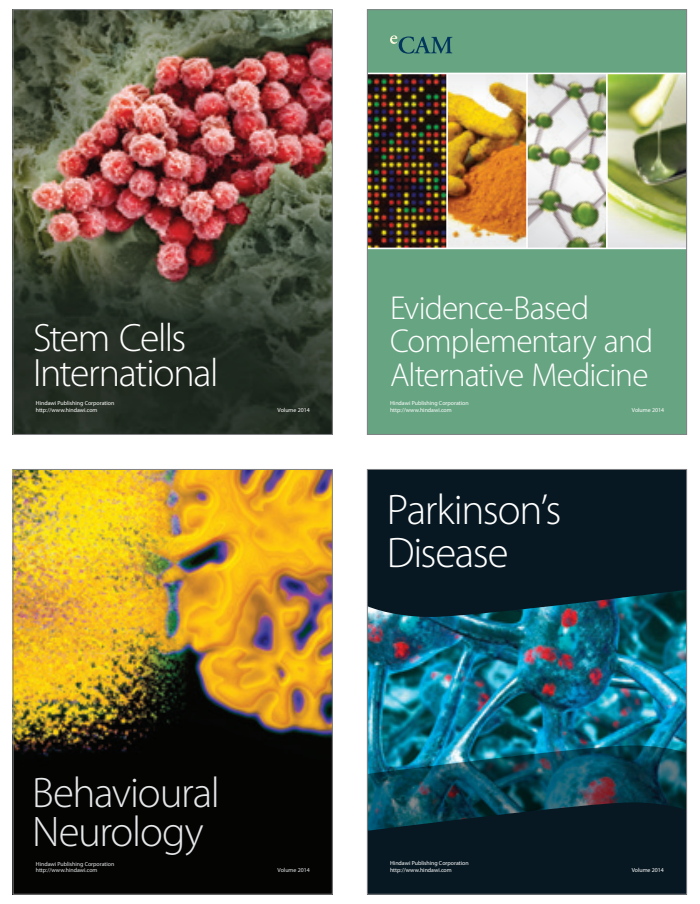
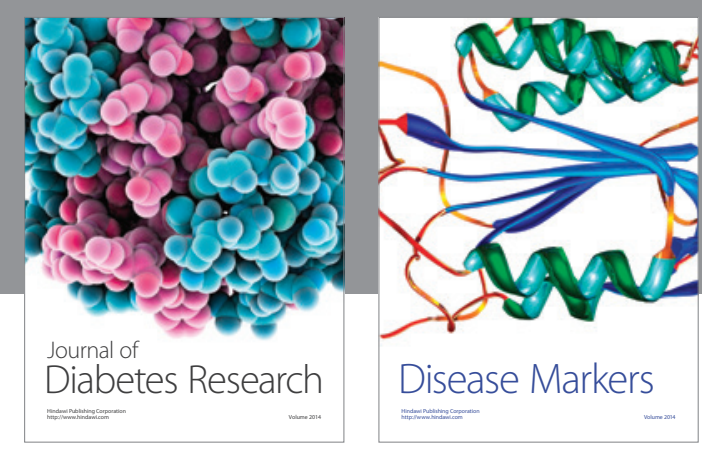

Disease Markers
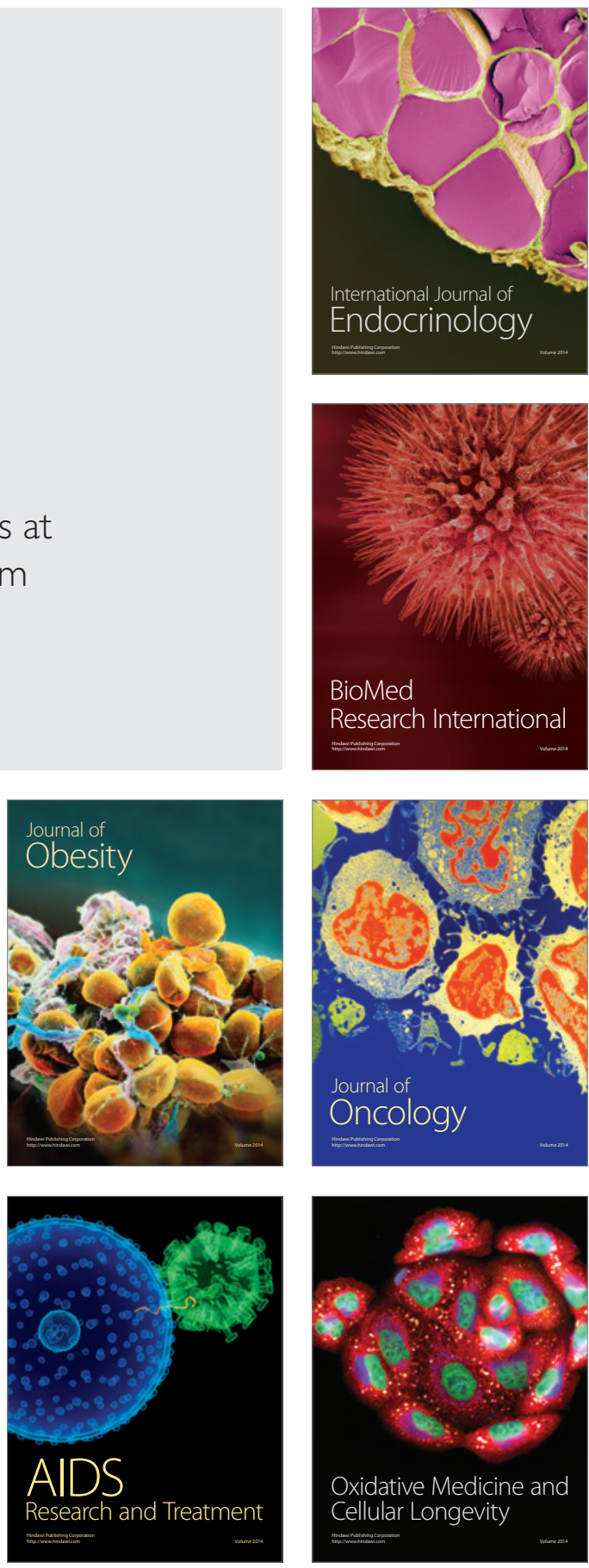